\title{
Grandmothers' role in preventing unnecessary accident and emergency attendances: cohort study
}

Emma Fergusson, Jun Li, Brent Taylor

Social support has an important effect on the way a family uses medical services. ${ }^{12}$ Grandmothers have been shown to influence discipline and care behaviour, ${ }^{3}{ }^{4}$ but possible effects of grandmothers on child health have been little studied. A small retrospective study from Philadelphia in the United States suggested that when grandmothers were involved in a child's care there was a greater use of accident and emergency services. ${ }^{5}$ Our impression was that the reverse was true in Britain and that grandmothers had a beneficial role in supporting mothers and young children. We decided to investigate whether an involved grandmother affected use of services in our accident and emergency department.

\section{Participants, methods, and results}

We used a telephone based questionnaire to study the families of 128 children aged 5 years or less with no older siblings who attended Royal Free accident and emergency department in July and August 1997. The study was approved by the local ethics committee.

We assessed the accident and emergency records to determine the outcome of attendance as no treatment (reassurance or paracetamol only-a probable minor or trivial problem) or treatment (any treatment apart from paracetamol, investigation ordered, or senior opinion requested-likely to reflect a serious problem). We contacted all families with recorded telephone numbers (101 children, 79\%) within three or four days of attendance at the department. All families (father in 24 cases) agreed to answer the questionnaire, which included details of the family structure and degree of contact with grandmothers. The voluntary and confidential nature of the study was made explicit. No one objected to being contacted, and data on all 14 precoded questions were complete.

Among the contacted families, 55 children received treatment and 46 received no treatment. For families not contactable by telephone, 12 children were treated and 15 were not. The table shows that children without an involved grandmother were more likely to attend with a problem not requiring treatment $\left(\mathrm{P}<0.001\right.$ on $\chi^{2}$ testing; adjusted odds ratio 8.82). Children of mothers with no formal educational qualification were also more likely to attend with conditions not needing treatment compared with mothers who had a formal educational qualification (odds ratio 3.94 ).

\section{Comment}

This study suggests that children who have a grandmother involved in their care are less likely to present to accident and emergency with minor or trivial conditions considered not to need treatment.

$\begin{aligned} & \text { Relation between likelihood of treatment when a child attended an accident and } \\
& \text { emergency department and grandmothers' involvement in the child's care and maternal } \\
& \text { education }\end{aligned}$
$\begin{aligned} & \text { Odds (No of children } \\
& \text { not treated/treated) }\end{aligned}$
\begin{tabular}{llc} 
Variables & Adjusted odds ratio† (95\% CI) \\
\hline Grandmother involvement: & $0.25(8 / 32)$ & 1.00 \\
\hline High & $1.65(38 / 23)$ & $8.82(3.12$ to 24.94$)$ \\
\hline Low & $0.67(33 / 49)$ & 1.00 \\
\hline Maternal education: & $2.17(13 / 6)$ & $3.94(1.19$ to 13.04$)$
\end{tabular}

†Adjusted for chronic medical problems, paternal involvement, and either maternal education or grandmothers' involvement. Other factors that initially seemed related - for example, grandmother living nearby and younger sibling were not significant in the final logistic regression model.

The telephone administered questionnaire was very successful, with no refusals among those contacted. Our results reflect a single inner city hospital population and the study was carried out over a short period during the summer so the findings may not apply elsewhere. Other variables such as involvement of the grandfather were not considered.

Our results suggest that grandmothers can provide reassurance for families with young children, reducing the likelihood of attendance with conditions not requiring treatment. As our society changes, with a loosening of extended family ties and increased mobility, the need for health professionals to fill the role of grandmother may increase.

Current training and standard textbooks include little on such topics. The absence of an involved grandmother in a child's care is one of the markers of family vulnerability which health care services might profitably take into account.

We thank the accident and emergency staff for their help with this study, Dr Ben Lloyd for comments on drafts, and the parents for their cooperation.

Contributors: $\mathrm{EF}$ did the pilot studies and interviews and is the study guarantor. JL prepared the data forms and did the statistical analysis. BT had the idea for the study. All authors helped with the study design and participated in the analysis and writing up.

Funding: None,

Competing interests: None declared.

1 Halfon N, Newacheck PW, Wood DL, St Peter RF. Routine emergency department use for sick care by children in the United States. Pediatrics 1996;98:28-34.

2 Horwitz SM, Morgenstern H, Berkman LF. The impact of social stressors and social networks on pediatric medical care use. Med Care 1985;23:946-59.

3 Tomlin AM, Passman RH. Grandmothers' responsibility in raising two year olds facilitates their grandchild's adaptive behaviour. Psychol Ageing 1989;4:119-21

4 Tomlin AM, Passman RH. Grandmothers' advice about disciplining grandchildren. Is it accepted by mothers and does its rejection influence grandmothers' subsequent guidance? Psychol Ageing 1991;6:182-9.

5 Ellen JM, Ott MA, Schearz DF. The relationship between grandmothers involvement in child care and emergency department utilization. Ped Emergency care 1995;11:223-5.
Royal Free Hospital, London NW3 2QG Emma Fergusson, paediatric senior house officer

Royal Free and University College Medical School, University College London, Royal Free Campus NW3 2PF

Jun Li,

research epidemiologist Brent Taylor, professor of community child health

Correspondence to: Dr Fergusson, Department of Child Psychiatry, Maudsley Hospital, London SE5 8AZ E.Fergusson@ iop.bpmf.ac.uk

BMJ 1998;317:1685 